\title{
Taking action: Implementing your written investment plan
}

\author{
Gabriel Lee BComm CIMA
}

W hen asked recently what I am writing about in this series of articles, I explained that each of the last few articles has outlined how the individual investor can apply one step of the six-step investment management consulting (IMC) process in their own portfolio. My colleague was surprised because it is typically affluent institutional or pension fund clients, known to be methodical - almost clinical - in their approach toward money management, who make use of the IMC process.

He laughed and asked why an individual investor would want to read a bunch of industry-specific rhetoric on an investment process developed for pension plans. "Why don't you write on current events and more topical issues of interest? Besides, if they learn these steps and procedures, your readers might not come to us for any further investment advice and counsel." In retrospect, I must concede that these are good questions, and ones that you may be asking yourself as you read this last article in the series.

In my first article in this series (1), I introduced the notion that "the most effective way to circumvent the common mistakes made by an affluent investor...is first to establish a prudent process or strategy and then stick with it."

Even the most sophisticated and experienced investors fall prey to common, needless mistakes, but many of these mistakes can be avoided for a more desirable outcome when clearly defined objectives are laid out and a proven process is put into action. Well aware that any investor must navigate through a myriad of decisions to reap the rewards of investing, I introduced the six steps of the IMC process as a framework and theoretical foundation that any investor can use for this purpose.

One common mistake is conducting a search for professional money managers to invest your portfolio without first having written an investment plan, or 'investment policy statement' (IPS). I have seen investors exert far too much time and energy searching for the money managers who have the best performance numbers without first considering whether that manager's mandate or style is even appropriate for their portfolio. How will last year's best performing small capitalization stock manager further your financial well being if your goals and objectives dictate that you should not even consider holding 'small-cap' stocks in the first place? Not having determined precisely what asset allocation will best support an investor's goals and objectives may result in investing too heavily in one asset class purely because of that investor's familiarity with that type of asset.

As we near the end of our odyssey through the IMC process, the four steps we have covered in previous issues are summarized as follows.

Step 1: Analysis of current position, goals, and objectives (2)

Step 2: Design of your optimal portfolio (3)

Step 3: Formalization of your investment policy (4)

Step 4: Research, selection and combination of professional managers (5)

The following two steps in the IMC process remain.

Step 5: Implementation of the IPS

Step 6: Monitoring and evaluation of your portfolio

Step 5 , or the implementation phase, makes up the remainder of our discussion.

At first, step 5 may appear to be one of the simplest and least taxing elements of a successful investment management process, but it is not without its costs and challenges, or its opportunities. Properly executed, it involves selling existing assets and replacing them to bring your portfolio into alignment with the optimal portfolio designed in step 2 of the IMC process.

If you have ever purchased any investments in the past, you have executed this step of the process whether you had a conceptual framework surrounding it or not. Regardless of what approach you used to arrive at your decisions or what vehicles of

Gabriel Lee is one of Canada's leading investment management consultants. In 1997, he became the eighth Canadian to receive the designation of Certified Investment Management Analyst (CIMA) from the Investment Management Consultants Association in conjunction with The Wharton Business School, University of Pennsylvania. Gabriel is currently an Associate Director with ScotiaMcLeod Inc and is in charge of the Investment Management Group in Edmonton. He can be reached at 888-814-4223, toll free, in North America.

Correspondence and reprints: Mr Gabriel Lee, Associate Director, ScotiaMcLeod Inc, Scotia Place, Main Floor, Suite M26, 10060 Jasper Avenue, Edmonton, Alberta T5J 3R8. Fax 780-413-7477, e-mail gabe_lee@scotia-mcleod.com 


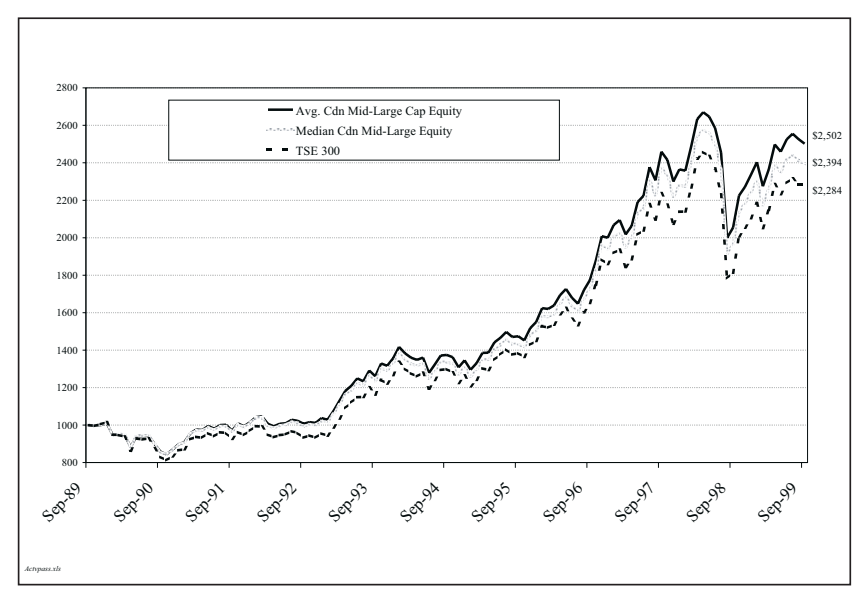

Figure 1) A ten-year perspective of active versus passive investment strategies in Canada. Note that all returns are gross of fees. Avg Average; Cap Capitalization; Cdn Canadian; TSE Toronto Stock Exchange. Reproduced with permission from Northern Trust Global Advisors, Inc

investment you selected, you must have undertaken some version of this step. Because the effective execution of this step is likely to have an important effect on investment results, it is prudent to understand some of the issues involved.

\section{BITING THE BULLET}

For most investors, implementation consists of simply 'biting the bullet' and putting real money into action. However, we can learn from people with successful pension plans who first complete a due diligence process, and then implement their IPS by proceeding with the investment options and strategies proposed by an investment management consultant.

This is an appropriate time to address, debate and resolve some remaining theoretical issues including passive versus active money management approaches; pooled versus separate account portfolios; dollar-cost averaging versus lump sum investing; and market timing versus strategic asset allocation.

Passive versus active investment strategies: Passive investing is also referred to as 'indexing'. It involves buying an investment product that contains the entire basket of securities that make up a particular index, such as the Standard and Poor's (S\&P) 500 or the Toronto Stock Exchange (TSE) 300. For example, if after a thorough assessment, the asset allocation calculated as optimal for a particular investor consists of $40 \%$ in Canadian equities, and the TSE 300 is selected as the appropriate benchmark against which to compare the performance of that portion of the portfolio, then a purely passive strategy would be to invest $40 \%$ of the portfolio in a TSE 300 index mutual fund.

This is in contrast with active management, where a money manager sorts through the universe of stocks and bonds, and selects only those that are appropriate for the investor's investment objectives as well as consistent with their own particular management style or investment specialty.

Indexing, or passive management, has been around for a long time but gained significant popularity in the late 1980s. Reviews of performance results of equity money managers through the 1980s suggested that some $60 \%$ of those managers 'underperformed the indexes' (6). This underperformance, cou-

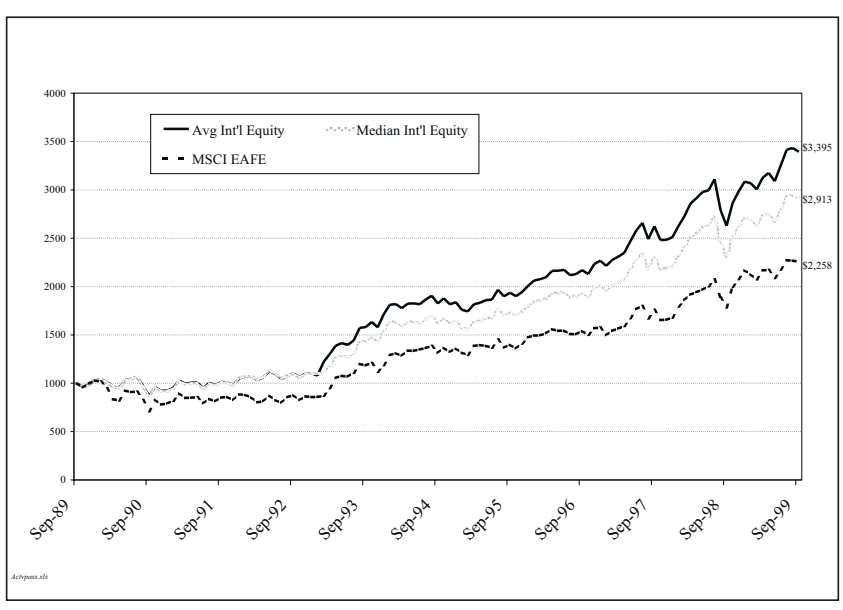

Figure 2) A ten-year perspective of active versus passive strategies internationally. Note that all returns are gross of fees. Avg Average; EAFE Europe Australia Far East; Int'l International; MSCI Morgan Stanley Capital International. Reproduced with permission from Northern Trust Global Advisors, Inc

pled with higher fees and transaction costs for active management, convinced many institutional investors to switch from active to passive management strategies.

In light of such research, some well known and respected academicians and practitioners supported the argument that using active management to try to beat the indexes was not worth the risk. However, the research on which many of them based their recommendations did not separate money managers into investment styles (such as value versus growth), nor did it categorize managers according to their average portfolio capitalization weightings (as in small capitalization versus large capitalization). All equity managers were grouped together and compared with a single index as the benchmark, the S\&P 500.

Had such variables been considered in determining which index to measure managers' performances against, the conclusions would undoubtedly have been different. Today, active equity managers typically build portfolios containing stocks that are not as large in capitalization weighting as those of the $S \& P$ 500. Therefore, when large capitalization American stocks perform well, as was the case in the mid- to late 1980s, the S\&P 500 index outperforms active managers. When mid-capitalization stocks perform well, thanks primarily to technology and Internet companies, as was the case in the late 1990s, active managers specializing in these stocks tend to outperform the S\&P 500.

It can be argued that the average mid to large cap Canadian equity active manager has not added much value to portfolios over the past 10 years (Figure 1). In fact, when management fees are included, active managers may have underperformed the index approach (using the TSE 300) over this 10-year time frame.

Either indexing or active management should be chosen for a portfolio by comparing managers' performance with indexes that provide a benchmark appropriate for those managers' particular styles. The S\&P 500 is a proper index to use as a benchmark in the case of 'large cap' equity managers, but obviously not for every equity manager. As the need for matching indexes to manager style becomes more widely recognized, less known indexes (such as the value and growth indexes of BARRA and 
Wilshire, respectively) are becoming more accepted and used in the marketplace and, therefore, more accessible in financial publications.

The Europe Australia Far East (EAFE) index is the most widely used benchmark for evaluating the performance of foreign equity money managers. It is interesting to note that international managers have performed much better than their Canadian counterparts compared with passive forms of money management (Figure 2). Some argue that there are more opportunities to capitalize on market inefficiencies in some of these less developed markets and that it is, therefore, easier to exploit over-reactions to market activities.

The advantages of indexing are as follows.

- An index mutual fund buys securities across all the sectors of the market represented by that index. This provides built-in diversification and avoids money manager risk because managers' areas of specialization tend to be more sector specific.

- For smaller investors, indexing may cost less to implement because purchases can be executed with mutual or pooled funds, and transaction and administrative costs are shared among all investors in the fund.

- Indexing allows for a great degree of certainty when matching the risk/reward profile of the investor to the performance measurement standards established in their written IPS.

The disadvantages of indexing are as follows.

- If a given market drops, the respective index fund will drop proportionately, whereas an actively managed portfolio with a basket of securities of superior quality may drop less than the market during that same correction.

- Active management can more readily take advantage of mispriced securities as investment opportunities.

- Indexing can lead to underdiversification when only well known indexes containing large capitalization stocks (TSE 300 or S\&P 500) are chosen. This can expose a portfolio to the 'large cap' bias inherent in choosing such indexes.

- When an active manager believes that securities have become overpriced, that manager has the option of increasing the size of the cash component in their portfolio. Then, if a correction occurs, the cash portion can cushion the portfolio from losses that would have been incurred had the portfolio been fully invested.

- Improved technology has made the development of indexing possible. The same technology has also made it possible to discover inefficiencies in the market that make indexing an imperfect practice. In other words, it is now possible for active managers to exploit the price inefficiencies in the markets caused by the buying or selling activity of large institutional investors when their trading of large blocks of securities moves stock prices dramatically up or down.

- The returns of an index fund always vary from the performance of the index it replicates, due primarily to three factors: the commission costs of executing purchases and sells within the fund; the fact that some portion of the fund will always be in cash, either awaiting investment or raised to meet redemptions; and the cost of management fees. This difference in performance and its causative factors are collectively referred to as the tracking error of the fund.

Pooled versus separate account portfolios: 'Pooled portfolios' are commonly referred to as mutual funds. As you probably know, they represent the combined assets of a group of investors with the same investment objectives, managed by an investment expert with a formally stated set of objectives. On the other hand, the 'separate account portfolios' referred to here are managed on a 'discretionary' basis by qualified professional money managers. 'Discretionary' refers to the managers' responsibility to make the day to day decisions and execute transactions on behalf of their clients as long as these decisions fall within the guidelines established in a contract between the client and the manager.

'Separate account portfolios' differ from most common investment accounts with a stockbroker in that it is rare for brokers to be qualified or licensed to manage accounts on a discretionary basis. According to securities regulations, brokers must ask for and receive consent on every transaction in a client's account before executing that transaction. Failure to do so is the practice of 'discretionary trading' by stockbrokers and can lead to not only serious penalties, but also, in extreme cases, the removal of their license to practice.

Over the long term, research has not shown any significant difference in performance between professionally managed separate account portfolios and mutual fund portfolios (7). Both can be used to implement an investment strategy effectively. However, some major differences between the two approaches should be considered when deciding between them.

Some of the differences between separately managed portfolios and mutual (or pooled) fund portfolios are outlined below.

Availability to the individual investor: Until recently, investors with smaller portfolios were unable to access the services of professional money managers and were often limited to purchasing mutual funds. Professional money managers typically establish minimum account size restrictions; these restrictions have been beyond the scope of all but the most affluent individual investors. On the other hand, the minimum amount required for an initial mutual fund purchase has decreased as the popularity of mutual fund investing has grown over the years, and some funds now require as little as $\$ 500$ to buy in.

Separate account managers have traditionally focused on providing services to institutional investors, managing the sizeable portfolios of defined benefit pension funds and large endowments. Most accomplished managers have an account size minimum of $\$ 1$ million or more. As their reputation and track record improve, a manager may continue to increase their account minimum. Some separate account managers may command minimums as high as $\$ 50$ million - far beyond the reach of the majority of investors.

A relatively recent development has led some of these managers to begin accepting accounts as low as $\$ 100,000$ when the responsibility for sales, marketing and client servicing is assumed by another organization, such as a brokerage or consulting firm. Money managers now realize that defined benefit 
pension plans are on the verge of extinction as newer corporations are choosing to opt out of establishing pension plans because of the increasing administrative costs of running them and increasing potential legal liability. These corporations are more often embracing what is known as the defined contribution market, where assets are employee funded and managed.

Suddenly, the burgeoning 'high net worth' baby boomer market is becoming more enticing to professional managers who traditionally have managed pension funds. Just as suddenly, the trust companies, insurance companies and banks, who are the traditional purveyors of services to high net worth individuals, have experienced heavy competition and have been forced to re-evaluate their often antiquated models of customer service and reporting.

Despite the relatively new availability of professionally managed separate accounts to individual investors, each investor must still decide whether this type of portfolio management is more appropriate for them than purchasing mutual funds.

Customization: The degree of customization available within a mutual fund portfolio is usually very limited. All unit holders of the mutual fund hold exactly the same units with exactly the same assets that reside within the portfolio. Separately managed accounts offer more flexibility, allowing each client to place their own constraints on a portfolio, permitting a greater degree of customization.

As an example, if you have a request of an ethical nature, such as not to invest in companies promoting the use of tobacco or alcohol, a separately managed portfolio can accommodate these requests, whereas a mutual fund would never change its stated mandate for one unit holder alone.

Costs: Most institutional investors, as well as increasing numbers of affluent individual investors, favour separate accounts over mutual funds because the amount paid by unit holders to cover the costs of administering mutual funds is directly proportional to the number of units held. Therefore, an investor who holds a large position in the mutual fund subsidizes the costs for smaller investors. With professionally managed separate account portfolios, the fee charged to investors with larger portfolios is a smaller percentage of the assets that they have placed with the manager.

Audits: Mutual funds are required to be audited by independent accounting firms. Separate account managers are encouraged to have performance results audited, but this is not required by law. Information and performance data are also more readily accessible on mutual funds than on private account managers.

Tax planning opportunities: With a separately managed account, a taxable investor has some degree of tax planning flexibility. At the year end, a money manager can be instructed to sell off stocks that have dropped in price so as to capture investment losses and offset investment gains realized in the portfolio in that tax year or previously. The stocks sold can be repurchased again after 30 days to maintain the integrity of the manager's portfolio and effect a 'tax swap'.

Phantom tax gain: Imagine that yesterday you became the owner of a given mutual fund, and that today the manager of that fund sells a particular stock that was held in the fund for several years. Suppose the stock was purchased at $\$ 30$ per share and sold at $\$ 75$ per share, resulting in a significant capital gain. For you as the investor, there existed an unrealized capital gain tax liability when you bought into the mutual fund. Because all investors who hold units of the mutual fund on the day the capital gains distribution is declared are hit with the same capital gain, you will participate in shouldering the tax burden of gains even if you bought in after the gains occurred.

Fund liquidation and purchases: Besides managing the securities portfolio of the mutual fund, the fund manager must contend with purchases by new investors and liquidations by existing shareholders. This can become a problem when major market movements occur and the unit holders of the fund begin to 'follow the herd'.

Rather than being able to purchase more securities at a discount in a down market, the manager may be forced to sell securities at fire sale rates to come up with the cash to cover liquidations, further depressing the net asset value of the mutual fund. Managers may at times hold a larger cash position than they would like in a fund because of the need to meet potential liquidations.

On the other hand, a large influx of cash from new investors may force the same manager to invest even when the markets are soft to prevent a larger cash position from pulling down the overall performance of the portfolio.

Diversification: Most equity mutual funds hold 80 to 120 different securities. In a separately managed stock portfolio, the number of securities is usually half that amount. For an investor who is comfortable with a bit more performance volatility in anticipation of greater returns, the more concentrated portfolio with fewer securities may be appropriate.

Tax deductibility of management fees: The management expenses and transaction costs incurred within a mutual fund cannot be deducted as an investment expense by the individual investor. These expenses are accounted for in calculating the net asset value of the fund. However, outside of a registered retirement savings plan (RRSP), individuals can claim the fees paid to a money manager of a separately managed account as part of their miscellaneous investment expense deductions.

Brokerage expenses: Mutual fund expense ratios, often referred to as management expense ratios, do not include the brokerage costs incurred to buy and sell securities in and out of the fund, nor do they include custodial fees charged by the trust company who acts as custodian of the fund. It is not uncommon for a mutual fund to generate significant transaction costs by turning over an entire portfolio frequently. In addition, the trading activity from ongoing new contributions and redemptions adds to brokerage expenses. All things considered, the total costs shouldered by investors in any given mutual fund can be very similar to those of a separately managed account.

Shareholder information provided: Investors with separately managed accounts receive annual and quarterly reports from the companies in which they hold shares unless they opt not to. This is appealing to investors who want to understand the stock analysis and selection process followed by the money manager to whom they have delegated their buy and sell decisions.

Mutual fund unit holders receive annual and quarterly reports detailing the security positions held by the fund. Typically though, very little information is provided about the specific companies whose stocks are held in the fund, their products and services or their financial situation.

Specific identification of securities: Even though, with profes- 
sionally managed separate accounts, investors are freed of the day to day buy and sell decisions, they are still informed of every transaction executed on their behalf. This is typically done by providing either a confirmation slip for every trade or a monthly custodial statement showing every transaction. The investor knows exactly what securities are in the portfolio. With a mutual fund, the shareholder receives less frequent reports showing total fund holdings.

Control over asset allocation: Because separately managed portfolios can be examined on a daily basis, it is relatively easy to monitor the manager's commitment to appropriate asset classes. By the same token, it is not unusual for mutual funds to drift from their perceived mandate, such as when equity mutual funds hold relatively high percentages of cash or when a perceived domestic equity or balanced fund holds international securities. The mutual fund manager may be betting his fund assets on market segments not previously used but permissible under the prospectus. Again, manager discretion may be overly broad in a mutual fund setting but more easily controlled in a separately managed account.

Fees and compensation: Often one of the most compelling reasons for high income investors with taxable investment accounts (those that are not RRSPs) to choose separate account portfolios over pooled or mutual fund portfolios is the desire to deduct portfolio management fees as an investment expense on income tax returns. With mutual funds, these fees are not tax deductible because they cannot be paid separately by each investor; they are incurred at the fund level, not the investor level.

Also, employment contracts for mutual fund managers tend to be structured so that the manager is provided with a bonus for outperforming his or her peer group. While there is little opposition to such an incentive, it may increase the temptation to take more risk or make major sector bets such as on technology stocks. Mutual fund managers are not required to disclose their exact holdings on an ongoing basis, and their portfolios can be shrouded in secrecy if they do not want competitors to know the fund's holdings.

Dollar cost averaging versus lump sum investing: Once money managers have been selected, either in the form of mutual fund managers or professional managers to whom you give discretionary power to make the day to day decisions in your investment accounts, the final decisions to be made are about the timing of the actual placement of cash into the fund or managed account.

Two options you need to choose between are 'dollar costaveraging' and 'lump sum investing'. When cost and performance of these approaches are evaluated, neither has been shown to be consistently preferable over the other.

'Dollar cost averaging' is the process of making multiple deposits of equal size at regular intervals over a specified period of time. This results in acquiring a particular type of asset slowly, which can decrease the risks of a sudden market downturn. Dollar cost averaging can be particularly useful when markets are unstable.

For the individual investor, cost averaging strategies are sometimes more feasible for purchasing mutual funds than for placement of money in separately managed accounts. As discussed previously in this article, in order to access the services of separate account managers, it is not unusual to have to meet a minimum initial account size requirement of $\$ 100$ thousand to $\$ 1$ million per mandate or manager.

'Lump sum investing' is exactly what you would expect investing all the money intended, as specified in the asset allocation determined in the second step of the IMC process, over days or weeks. Some believe that this approach is preferable to dollar cost averaging, which is seen by proponents of lump sum investing as attempts at market timing; they argue that short term market fluctuations have a negligible effect on the portfolio's performance over the long term. As well, advocates of lump sum investing suggest that delays in getting into the market expose the investor to the risk of lost opportunity.

Market timing versus strategic asset allocation: Fiduciaries, individual investors and investment consultants usually have quite different opinions on most investment management subjects. However, the subject of market timing is not one those subjects.

'Market timing decisions' involve moving funds in or out of the stock markets in an attempt to enhance returns. The compelling lure of buying low and selling high is often so attractive to inexperienced investors that they often fall victim to market timing attempts, despite evidence that clearly shows this approach as an ineffective way to increase returns consistently. "Though attempts at market timing exist, the overwhelming consensus is that market timing is a fool's game since it is statistically improbable that some system or someone can consistently time when to be in or out of the market" (8).

To add value to a portfolio, a market timing strategist must successfully perform each of the following seven functions: identify where current economy is positioned in the context of a full market cycle; identify the factors that will affect the value of securities within each asset class - stocks, bonds and treasury bills; identify which asset classes will realize the best advantage from anticipated economic and political changes; weigh the exposure to each asset class; make appropriate decisions to realize capital gains by selling assets that have appreciated while factoring in the tax consequences; redeploy the liquidated assets to exploit upcoming economic changes; and minimize performance erosion by controlling transaction costs.

It is hard to imagine a more daunting task in this world of constant change than to succeed consistently in the practice of each of the above points.

'True market timing' involves total or large scale shifts in the portfolio's allocation among stocks, bonds and cash. When the market timer is bullish, $100 \%$ of the portfolio is invested in stocks. Conversely, when the timer anticipates a market correction, $100 \%$ of the portfolio is invested in cash.

In a study supporting asset allocation instead of market timing, Brinson et al (9) examined the 10-year performance of 91 large American pension plans. The results show that, on average, market timing actually cost the pension plans $0.66 \%$ or 66 basis points of annual average return over a decade. The most fortunate pension plan added just 25 basis points from market timing, and the most hapless plan forfeited 268 basis points annually over a decade. Do not forget that these costs were incurred in nontaxable pension portfolios. If we include the impact of capital gains tax as entire portfolios are sold and then rebought, the results would be even more unappealing. 
Figure 3 shows that consistent participation in the S\&P 500 index over a five-year period was remarkably more rewarding than taking the risk of missing just the 30 'best days' during that same time frame. Over a longer time frame of the past century, the S\&P 500 has risen approximately $70 \%$ of the time. This suggests that by pulling out of the market and remaining in a cash position, aspiring market timers stand to be wrong seven times out of 10. "It doesn't help the long-term investors to be pulled out of the market before a crash, only to miss the inevitable bull market that follows"(10).

A more favourable alternative to market timing is strategic asset allocation. In step 2 of the IMC process, a specific plan is calculated for allocating investments among stocks, bonds and cash for a particular investor and represents the optimal portfolio for that investor. The optimal portfolio is one that provides the highest return with the least amount of investment risk that is consistent with your risk tolerance.

Practising strategic asset allocation instead of market timing allows you to stay within your own specific risk/return parameters. This is done by rebalancing the portfolio as necessary when changes in market values result in as little as plus or minus 5\% variation in the asset class allocations. Significant variation from the initial asset allocation plan can markedly affect the returns and the amount of risk contained within the portfolio.

Although there may have been a time when it was possible to have an advantage of more or faster information with which to time buying or selling, it is rare today. Technology and the speed with which information travels have been referred to as the 'great equalizers' of the 20th century. Effective market timing will continue to become even more difficult.

\section{THE END OF A SERIES AND THE BEGINNING OF A JOURNEY}

Upon addressing, debating and resolving the aforementioned topics and issues, the portfolio building process will be complete. Investment policy has been developed, macro- and microexpectational factors relevant to investing have been identified, portfolio composition has been decided, and assets have been allocated and optimized. This is where your real financial journey begins.

As I approach the end of an odyssey that began almost a year ago in the May, 1999 issue of this journal (11), I again ponder whether I have done the right thing by delving into a practical step by step description of the IMC process.

To address the question about why I specifically chose not to write about current events and more topical issues of interest, my answer is as follows. In my tenure as an investment advisor, I have seen this profession attract some of the most successful sales professionals in the country and, among them, some of the most gifted raconteurs I have had the pleasure of meeting. Some of these individuals are far more gifted than myself at relaying current topical events, which would make for superior light reading. I can truly say, though, that most investors I have had the pleasure of dealing with stood to benefit from additional awareness of factual research, education and planning. Armed with the fundamentals of the IMC process, investors can be in a more empowered state of financial awareness, more capable of

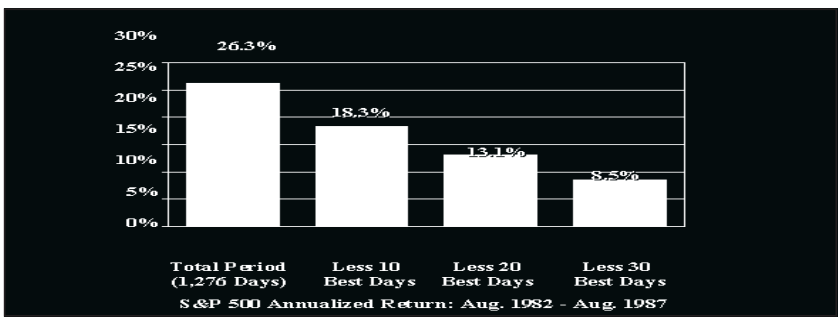

Figure 3) The risks of market timing

making the critical decisions necessary to nurture and maintain a successful portfolio. There is plenty of financial gossip, fruitless speculation and conjecture available to bemuse and bewilder the most avid 'hot tip' collector. It will serve no one to have me adding more fuel to that glowing fire.

My bias is strongly in favour of this process and methodology over any other approach that I have found, explored or practised. Although the IMC process is by no means the only process available, I believe that it is one of the few timeless and sufficiently flexible procedures that may be followed by almost any investor to manage investment decisions successfully and yield consistent, superior investment results. The vast array of choices to be made by investors can understandably result in financial paralysis from information overload. The IMC process offers a way to distinguish valuable enhancements to your future financial well being from the occasional futile, and sometimes counterproductive, innovations of Wall Street and Bay Street.

I hope that these articles have sparked some additional interest in the area of investment management, identified potential areas of weakness in your current process or structure such that some mistakes may be averted or some opportunities seized, and provided some new distinctions on how to create more prosperity in your life.

Many thanks for your consideration. May your journey offer you many full and rich experiences.

\section{REFERENCES}

1. Lee G. Common mistakes of affluent investors and how to avoid them. Can J Gastroenterol 1999;13:521-4.

2. Lee G. How to reap benefits from other people's money. Can J Gastroenterol 1999;13:618-21.

3. Lee G. Does your investment portfolio need an efficiency tune-up? Can J Gastroenterol 1999;13:689-94.

4. Lee G. The plan - Formalizing your unique 'investment policy'. Can J Gastroenterol 1999;13:779-83.

5. Lee G. Stalking the elusive investment guru. Can J Gastroenterol 1999; 13:65-9.

6. Trone DB, Allbright WR, Taylor PR. The Management of Investment Decisions. Chicago: Irwin Professional Publishing, 1996:174.

7. Trone DB, Allbright WR, Taylor PR. The Management of Investment Decisions. Chicago: Irwin Professional Publishing, 1996:176.

8. Trone DB, Allbright WR, Taylor PR. The Management of Investment Decisions. Chicago: Irwin Professional Publishing, 1996:185.

9. Brinson GP, Hood LR, Beebower GL. Determinants of portfolio performance. Financial Analysts Journal 1986;July/August:39-44.

10. Trone DB, Allbright WR, Taylor PR. The Management of Investment Decisions. Chicago: Irwin Professional Publishing, 1996:188.

11. Lee G. Are you as wealthy as you should be? Can J Gastroenterol $1999 ; 13: 303-4$

Readers who wish to obtain a copy of Gabe Lee's article "Monitoring and evaluation", outlining the sixth and final step of the IMC process, should contact him directly at the address on page 146. 


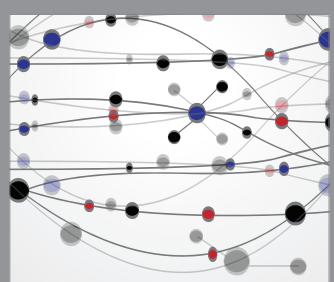

The Scientific World Journal
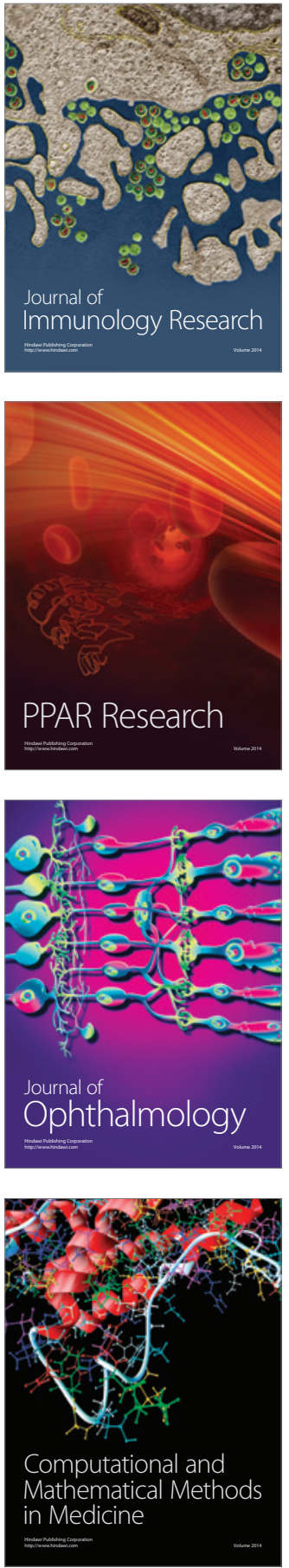

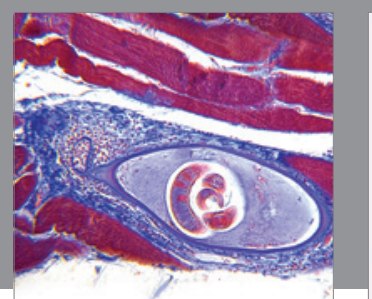

Gastroenterology Research and Practice

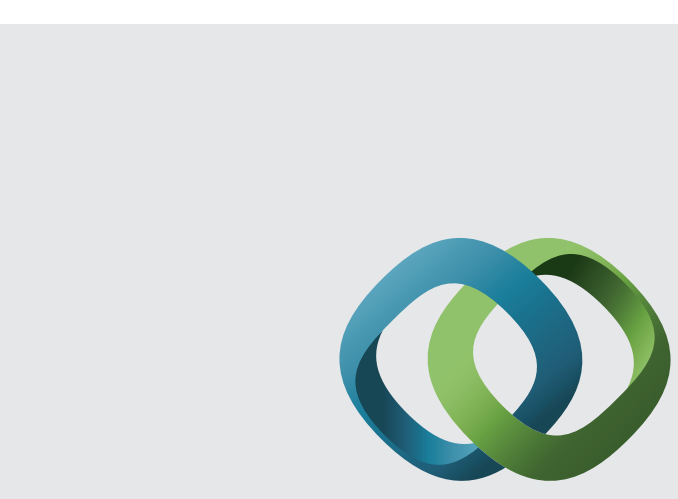

\section{Hindawi}

Submit your manuscripts at

http://www.hindawi.com
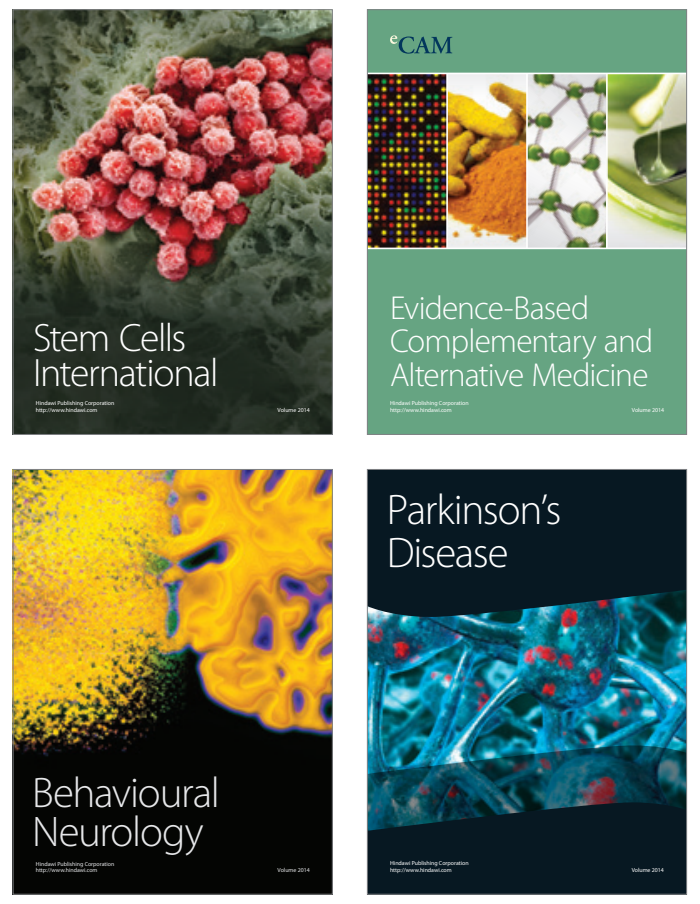
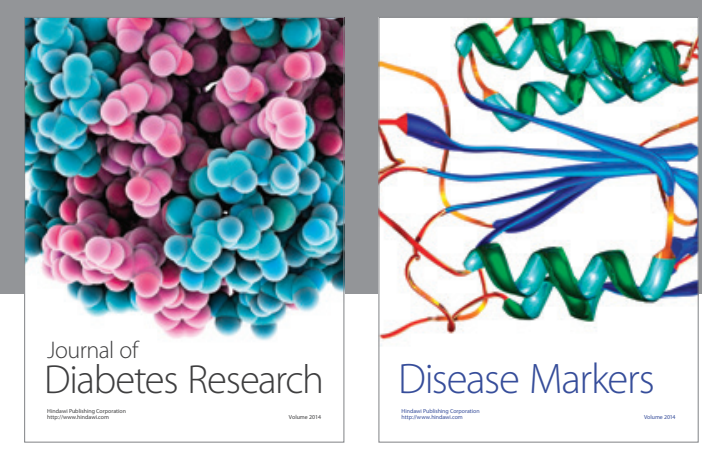

Disease Markers
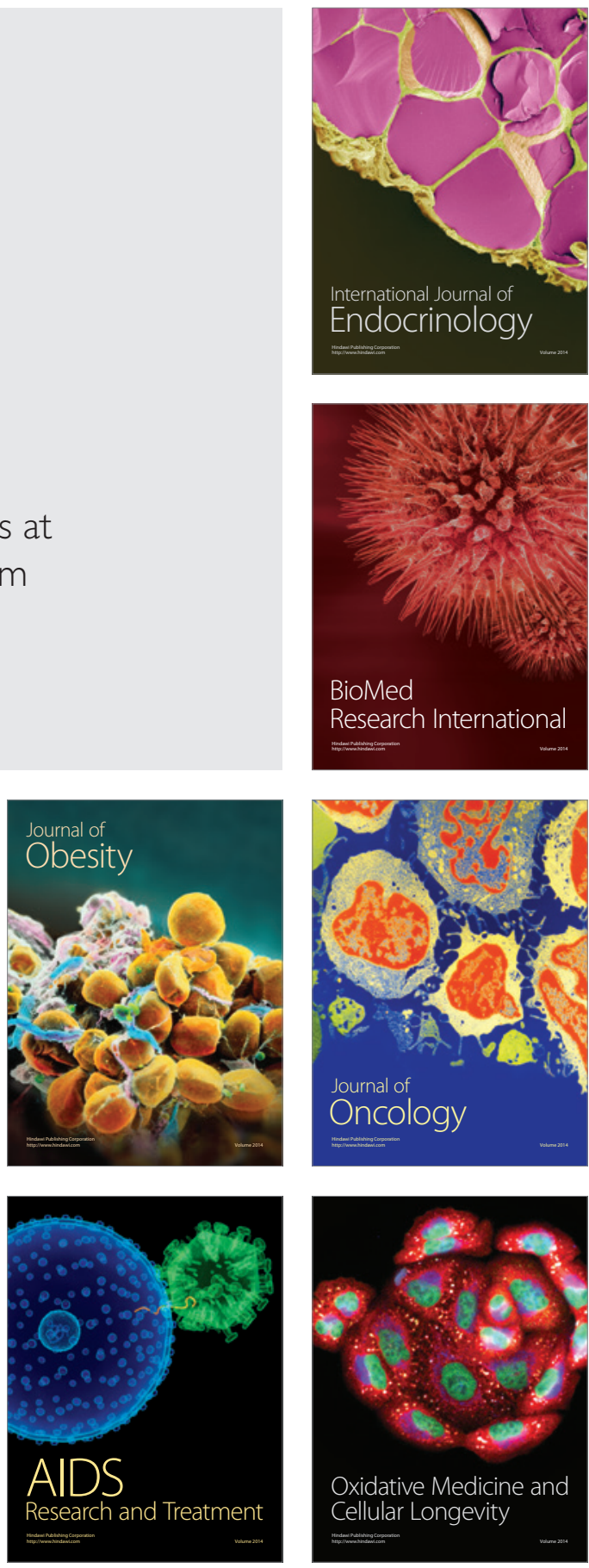